\title{
EAGLE'S SYNDROME: OUR CURRENT EXPERIENCE OF THE DISEASE AND LITERATURE REVIEW
}

\author{
Mohammad Shakeel1, Iram Khan², Gaurav Kumar ${ }^{3}$, Ritu Sharma ${ }^{4}$ \\ ${ }^{1}$ Associate Professor, Department of ENT, Era's Lucknow Medical College and Hospital, RML Avadh University, Lucknow. \\ ${ }^{2}$ Associate Professor, Department of Forensic Medicine \& Toxicology, HIMS, RML Avadh University, Lucknow, India. \\ ${ }_{3}^{3}$ Assistant Professor, Department of ENT, TSM Hospital \& Medical College, Lucknow, India. \\ ${ }_{4}^{4}$ Assistant Professor, Department of Pathology, HIMS, RML Avadh University, Lucknow, India.
}

\begin{abstract}
Eagle's syndrome is a disease caused by an elongated styloid process or calcified stylohyoid ligament. Eagle defined the disorder in 1937 by describing clinical findings related to an elongated styloid process, which is one of the numerous causes of pain in the craniofacial and cervical region. These symptoms can mislead the otolaryngologist in diagnosing the condition. The prevalence of individuals with this anatomic abnormality in the adult population is estimated to be $4 \%$ with $0.16 \%$ of these individuals reported to be symptomatic. Radiological examinations are useful to make the accurate diagnosis. Three-dimensional computed tomography (CT Scan) is the most valuable diagnostic tool. Patients with increased symptom severity require surgical excision of the styloid process styloidectomy, which can be performed through an intraoral approach.
\end{abstract}

\section{KEYWORDS}

Elongated Styloid Process, Eagle’s Syndrome, CT Scans, Styloid Process, Styloidectomy.

HOW TO CITE THIS ARTICLE: Shakeel M, Khan I, Kumar G, et al. Eagle's syndrome: our current experience of the disease and literature review. J. Evolution Med. Dent. Sci. 2016;5(25):1319-1323, DOI: 10.14260/jemds/2016/310

\section{INTRODUCTION}

According to Eagle $4 \%$ of the human population have an elongated styloid process, which includes symptomatic and non-symptomatic variety, i.e. anatomical variations. And only $4 \%$ of the above trait presents with multiple symptoms.[1,2] such as feeling of a foreign body lodged in the throat, difficulty and pain during swallowing, persistent throat pain, pain on turning the head, pain referred to infraorbital, infratemporal, ear and occipital areas, pain on wide opening of mouth, headache, tinnitus, recurrent pain in the oropharynx, face and referred otalgia.[3,4,5] The styloid process is a slender outgrowth at the base of the skull in the temporal bone, immediately posterior-medial to the mastoid apex arising from the inferior surface of the temporal bone at the junction of its petrous and tympanic portions.[6,7]

Eagle defined the length of a normal styloid process at 2.5-3.0 cm. The styloid process may vary in length and sometimes stylohyoid ligament may also ossify from its origin at the styloid process to its attachment at the hyoid bone mimicking elongated styloid process.[8] Eagle considered any styloid process longer than $25 \mathrm{~mm}$ in an adult to be abnormal, which may be symptomatic or non-symptomatic. Nonsymptomatic elongated styloid processes are encountered during head and neck radiological investigations, cadaveric dissections and autopsy leading to above estimations of prevalence. Nanjundaiah et al. encountered elongated styloid process in two routine cadaveric dissection aged around 5560 years. ${ }^{[9]}$

Financial or Other, Competing Interest: None.

Submission 12-02-2016, Peer Review 08-03-2016,

Acceptance 14-03-2016, Published 25-03-2016.

Corresponding Author:

Dr. Gaurav Kumar,

H/No. 1404 HIG, Sector-I,

LDA Colony, Kanpur Road,

Lucknow-226012,

Uttar Pradesh,

India.

E-mail: kumargaurav.1014@gmail.com

DOI: $10.14260 /$ jemds $/ 2016 / 310$
Eagle's syndrome was initially defined in 1937 by an otolaryngologist Eagle. ${ }^{[5,10]}$

He divided the syndrome into two forms: Classic type and carotid artery type styloid. The classic type can develop after tonsillectomy, when scar tissue under the tonsillar fossa compresses and stretches cranial nerves V, VII, IX and X and presents with symptoms such as foreign body sensation, pain being referred to the ear and dysphagia.

The carotid artery type of Eagle's syndrome presents with other symptoms, such as migraines and neurological symptoms caused by irritation of the sympathetic nerve plexus and compression of carotid vessels. If the internal carotid artery is compressed, then ipsilateral headaches can occur and if external carotid artery is compressed then there can be pain in the temporal and maxillary branch areas.[11,12]

\section{Case Report 1}

A 38 years old male came into the Otorhinolaryngology OPD of ELMC and $\mathrm{H}$, Lucknow, with chief complaints of radiating pain in neck on right side for the last 3 years which gets aggravated during meal and jaw movement. Since then he was on conservative management, but was never relieved of his symptoms completely. No other significant medical history present. Previous endoscopy report and X-ray neck were inconclusive. Intraoral examination revealed poor oral hygiene and on palpation of bilateral tonsillar fossa tender and elongated styloid process was felt on right side, while elongated styloid process was felt on left side also, but not tender. Cotton soaked with $4 \%$ xylocaine was kept into the tonsillar fossa, symptoms subsided after few minutes and hence clinical diagnosis of elongated styloid process (Eagle's diseases) was made which was confirmed later on by imaging, i.e. Computed tomography. Three dimensional (3D) images were taken showing bilateral styloid process enlargement. Styloid length on right side was $52 \mathrm{~mm}$ and on left side it was $45 \mathrm{~mm}$ [Figure 1]. As per advice he underwent bilateral intraoral surgical excision of the process [Figure 2] and was relieved of the symptoms during followup for 3 weeks. 


\section{Case Report 2}

A 35 years old male came into the Otorhinolaryngology OPD of ELMC and H, Lucknow, with chief complaints of radiating pain in neck and throat laterally for the last 2 years which gets aggravated during solid meal and on sideways movement. Since then he was on conservative management, but was never relieved of his symptoms completely. No other significant medical history present. Previous endoscopy report and X-ray neck were inconclusive. Intraoral examination revealed poor oral hygiene and on palpation of bilateral tonsillar fossa, tender and elongated styloid process was felt. Cotton soaked with $4 \%$ xylocaine was kept into the tonsillar fossa, symptoms subsided after few minutes and hence clinical diagnosis of elongated styloid process (Eagle's diseases) was made, which was confirmed later on by imaging, i.e. Computed tomography. Three dimensional (3D) images were taken showing bilateral styloid process enlargement. Styloid length on right side was $35 \mathrm{~mm}$ and on left side it was $37 \mathrm{~mm}$ [Figure 3]. As per advice he underwent bilateral intraoral surgical excision of the process and was relieved of the symptoms during followup for 3 weeks.

\section{Case Report 3}

Another male patient, 42 years of age came into the Otorhinolaryngology OPD of ELMC and H presented with pain in bilateral submandibular region and headache, which gets aggravated while taking food and also having a foreign body sensation in throat with referred pain in bilateral ear since 5 years. He took conservative treatment from different practitioners, but was never relieved of his symptoms completely. Her previous X-ray neck did not reveal anything significant. Intraoral examination revealed poor oral hygiene with palpation of tender and elongated styloid process in bilateral tonsillar fossa. Extraoral examination did not reveal any specific findings. Above symptoms were subsided by application of $4 \%$ xylocaine within the tonsillar fossa. This confirmed our clinical diagnosis of elongated styloid process (Eagle's diseases), which was again reconfirmed by imaging computed tomography. On three dimensional images, bilateral styloid enlargement was seen measuring about $35 \mathrm{~mm}$ on right side and $33 \mathrm{~mm}$ on left side [Figure 4]. After informed consent, intraoral bilateral excision of styloid process was done. His symptoms decreased in severity within $24 \mathrm{hrs}$., but mild discomfort continued for another 2 weeks in the operated region which subsided completely later on during followup.

\section{Case Report 4}

Another patient 37 years of age, female, came into ENT OPD of ELMC and H presented with difficulty and pain in deglutition of solid food along with left side earache and throat irritation since three years. Intraoral examination revealed tenderness and elongated styloid process in the left tonsillar fossa only. She was under conservative treatment since three years, but was never completely relieved. According to her, she was diagnosed as a case of elongated styloid process and was advised and referred to our centre for further investigation and surgery of the same. Extraoral examination did not reveal any specific finding. Her symptoms subsided by application of $4 \%$ xylocaine in the left tonsillar fossa. Clinical diagnosis of elongated styloid process (Eagle's diseases) was made, which was confirmed by imaging computed tomography showing styloid enlargement on the left side. Length on right and left side was $27 \mathrm{~mm}$ and $34 \mathrm{~mm}$ respectively [Figure 5]. She was explained about the surgical procedure and after informed consent unilateral left-sided styloidectomy by intraoral route was done under general anaesthesia. She was relieved from the pain within $24 \mathrm{hrs}$., but foreign body sensation left side of the throat is persisting during followup.

\section{Case Report 5}

Another male patient, 24 years of age, came into the Otorhinolaryngology OPD of ELMC and $\mathrm{H}$ presented with pain in left neck, submandibular region and also having a foreign body sensation in throat from last six months. X-ray neck did not reveal anything significant. Intraoral examination revealed elongated styloid process in left tonsillar fossa. Extraoral examination did not reveal any specific findings. Above symptoms were subsided by application of $4 \%$ xylocaine within the tonsillar fossa. This confirmed our clinical diagnosis of elongated styloid process (Eagle's diseases), which was again reconfirmed by imaging computed tomography. On three dimensional images, bilateral styloid enlargement was seen measuring about $38 \mathrm{~mm}$ on right side and $44 \mathrm{~mm}$ on left side [Figure 6]. Patient was kept on conservative medical management and reassurance was given. On regular followup, pain subsided and no fresh complaint from the patient.
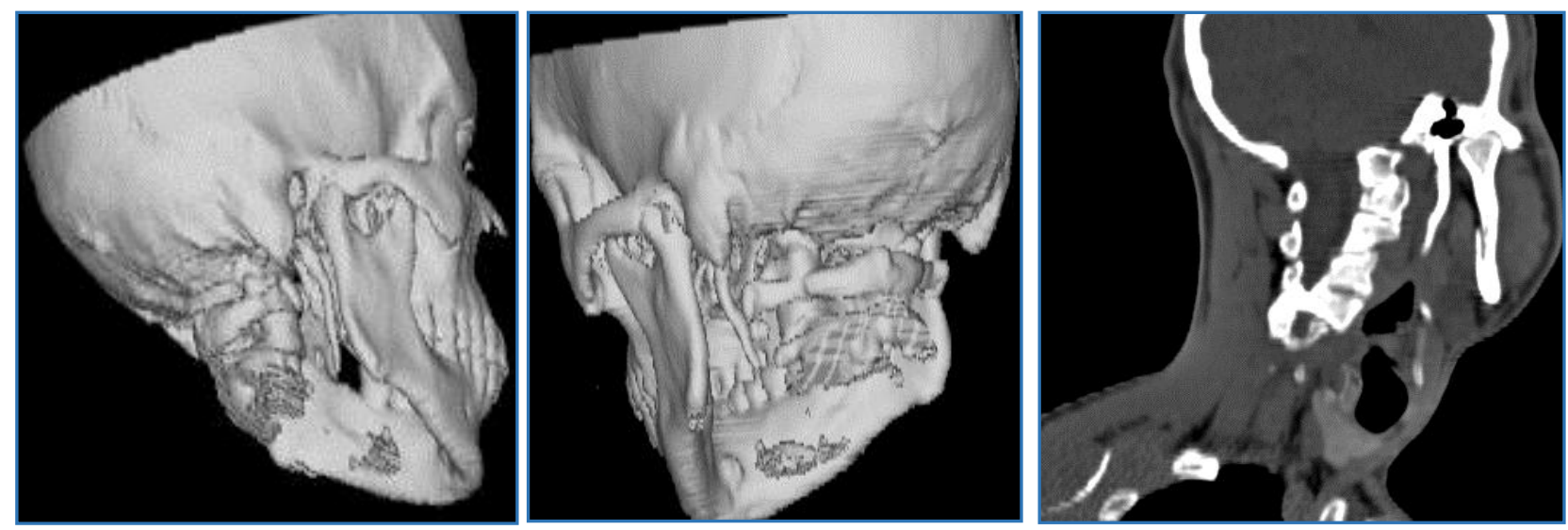

Fig. 1: Showing 3D and Sagittal Image of Elongated Styloid of $1^{\text {st }}$ Patient 

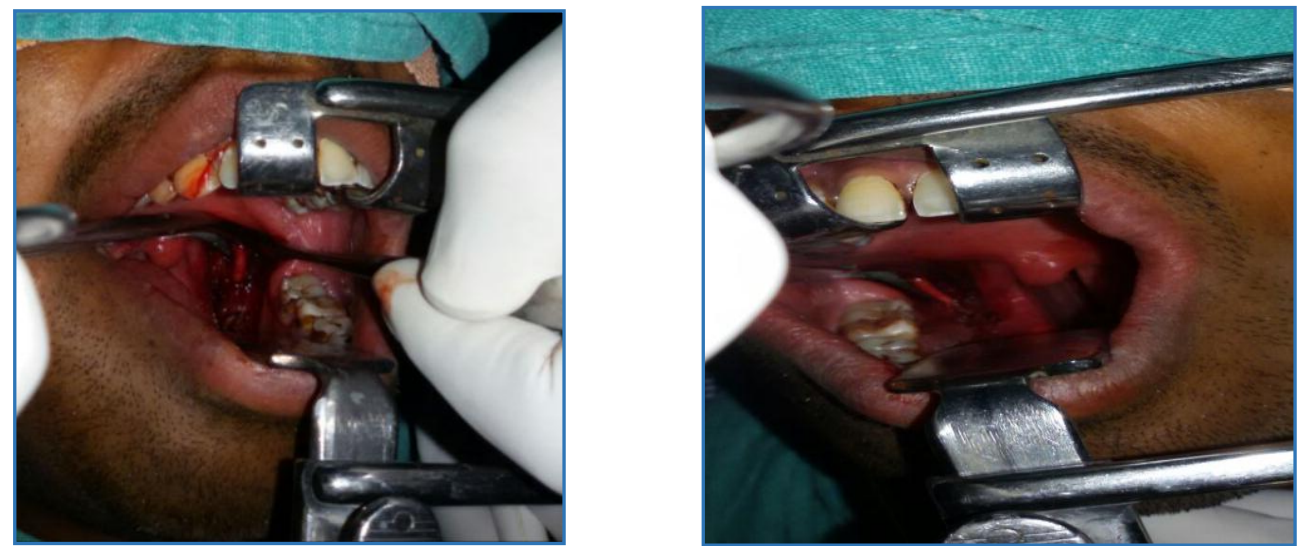

Fig. 2: Showing Peroperative Image of Right \& Left Styloid during Styloidectomy of $1^{\text {st }}$ Patient
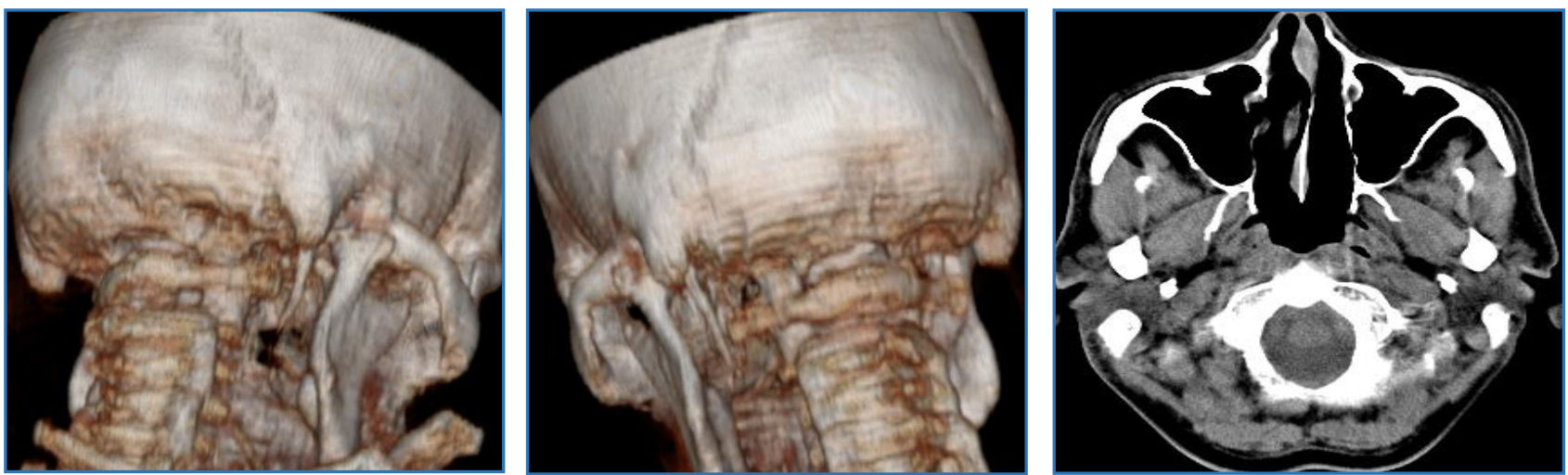

Fig. 3: Showing 3D and Axial Image of Elongated Styloid of 2nd Patient
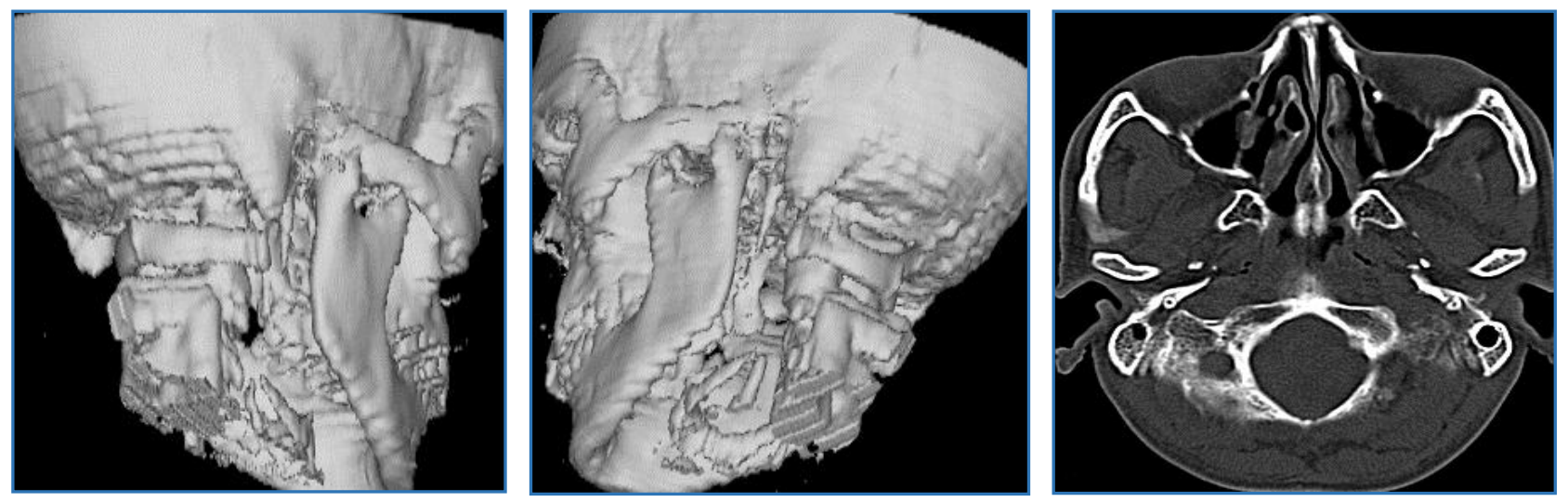

Fig. 4: Showing 3D and Axial Image of Elongated Styloid of $3^{\text {rd }}$ Patient
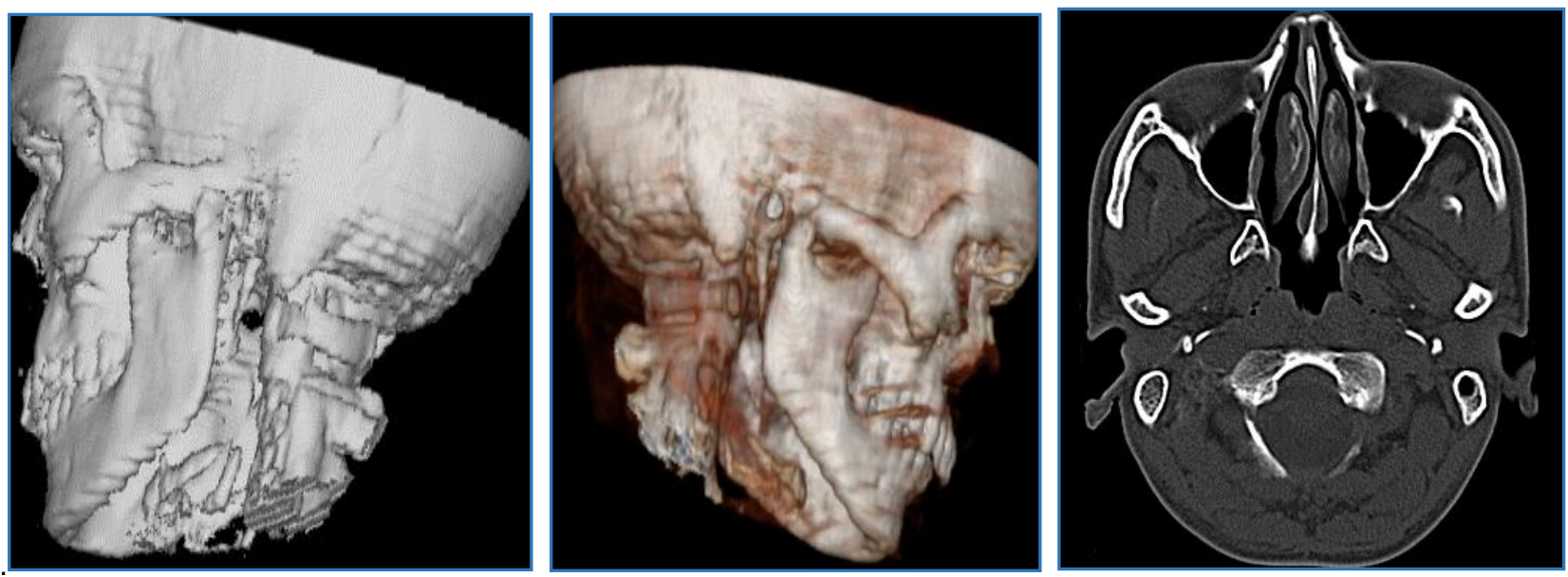

Fig. 5: Showing 3D and Axial Image of Elongated Styloid of $4^{\text {th }}$ Patient 

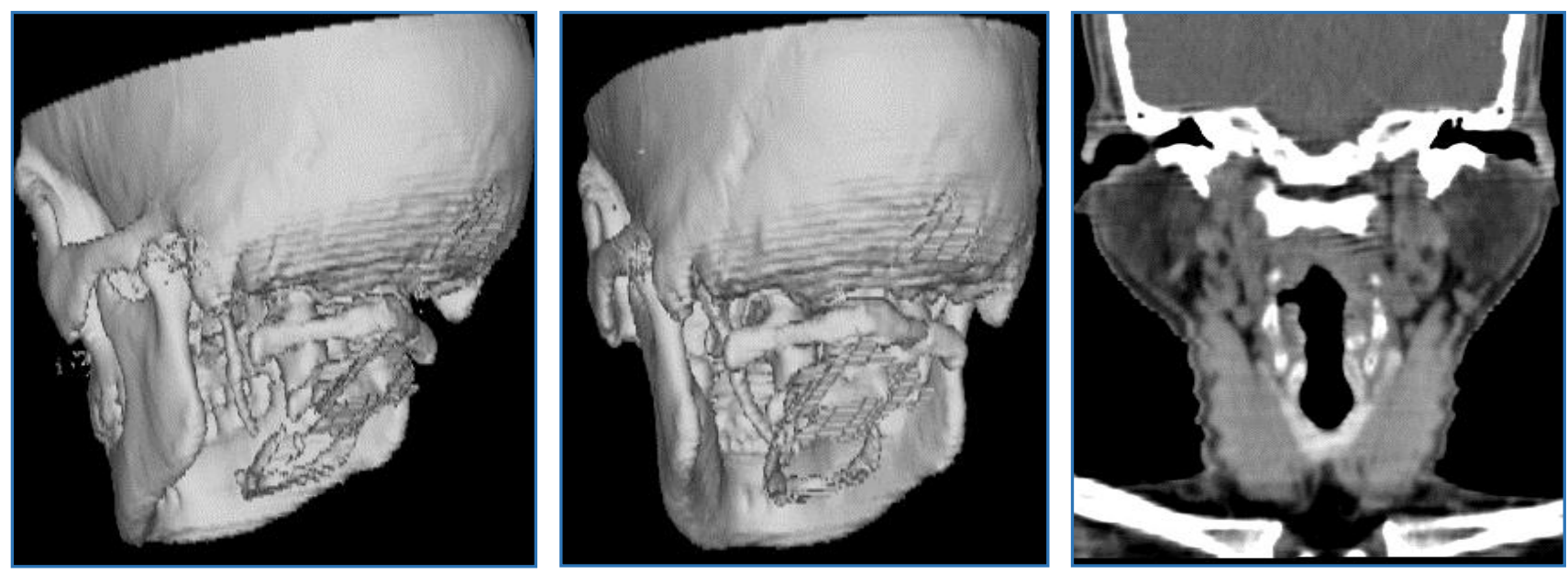

Fig. 6: Showing 3D Image of Elongated Styloid of Left Side of 5th Patient

\section{DISCUSSION}

The first mention of elongated styloid process as a clinical entity in literature was done by Lucke and Weinlecher.[4,5] Styloid process is part of the temporal bone lying anteromedial to the mastoid process measuring about $2-3 \mathrm{~cm}$. Embryologically, it is a derivative of the second branchial arch along with styloid ligament and the lesser cornu of the hyoid bone.[6,7]

Anatomical variations in the length of the styloid process and its stylohyoid chain are of profound anatomical, anthropological as well as of clinical importance. The stylohyoid chain extends between the temporal bone and hyoid bones and is divided into 4 sections; Tympanohyalwhich forms the base of the styloid process, Stylohyal-which forms major portion of the styloid process, Ceratohyal-which forms the stylohyoid ligament, Hypohyal-which forms the minor horn of the hyoid bone. The first two sections form the stylohyoid process.

Eagle's Syndrome or Styalgia caused by elongated styloid process is an uncommon and underdiagnosed clinical entity often presenting with vague pain in the throat, facial pain, referred otalgia and difficulty in swallowing. $[5,13,14]$ Extensive review of literature shows widespread terminology being used to express the elongation of styloid process with calcification of stylohyoid chain accepted by most of the authors. Keur et al. stated that if the length of the process or the mineralized part of ligaments as seen in radiographs was $30 \mathrm{~mm}$ or more it can be called as elongated styloid process.[15]

Jhakar et al. reported a case of unexceptionally elongated styloid process of size $82 \mathrm{~mm}$, found during the autopsy of male dead body in which cause of death was hanging. They emphasized the importance of early identifications of stylohyoid ossification adding that any over pressure at the surrounding area by medical, paramedical and physiotherapist may lead to fracture and clinical consequences.[16]

The cause of elongated styloid process is not well understood, but several theories have been put forward. The most popular one is growth of the osseous tissue along stylohyoid ligament. Ossification can take place during childhood and adolescence when the rate of bone growth is increased and after the age of 20 there is a rapid decrease in ossification formation.[17] However, other authors support that an inconsistent trend exists toward greater ossification of the stylohyoid ligament with advanced age.[18]
Symptoms of styalgia may be due to previous trauma or an inflammatory process that forms granulation tissue, resulting in the calcification or ossification of the stylohyoid ligament.[19] Steinman has proposed three theories to explain the ossification of the Stylohyoid ligament. The theory of Reactive Hyperplasia states that trauma can cause such ossification; the theory of Reactive Metaplasia which explains that it is a posttraumatic healing response and theory of anatomic variance which states that such ossification is an anatomical variation that occurs without any recognizable trauma.[20]

Langlais et al.[13] classified elongated Styloid process as Type I which is uninterrupted elongated Styloid process, Type II which is a pseudo-articulation between Styloid process and Stylohyoid ligament and Type III in which there are interrupted segments of the mineralized ligament creating the appearance of multiple pseudoarticulations. Another classification described four types of elongated styloid process depending upon amount of calcification as calcified outline, partially calcified, nodular complex and completely calcified. Patients may present with symptoms mainly headache, dizziness, earache and are usually due to direct compression of the adjacent nerves, mainly glossopharyngeal, lower branch of trigeminal and the chorda tympani nerve. Pain may also be due to proliferation of granulation tissue after a traumatic fracture of the styloid process leading to tendinosis or impingement on the carotid vessels. [19,21]

Pathogenic mechanisms for pain arising from an elongated styloid process may also involve impingement of the pharyngeal mucosa, as it is drawn against an elongated process during normal function or impingement of the carotid vessels and their associated sympathetic chain. ${ }^{[22]}$ Another mechanism of pain is due to "Constant mechanoreceptor discharge in the area of the $5^{\text {th }}, 7^{\text {th }}, 9^{\text {th }}$ and $10^{\text {th }}$ cranial nerve endings" initiated by a mechanical irritation from the styloid process.[23] The differential diagnosis for symptomatic elongated styloid process should include Glossopharyngeal and Sphenopalatine neuralgia, Temporomandibular joint disease, Migraine headaches, Temporal arteritis, Myofascial pain, impacted molar teeth and Faulty dental prostheses. Diagnosis can be made by clinical examination and plain radiography along with CT scan. The length of the styloid process is better demonstrated on lateral views, because there is less superimposition.[15,21,24] 
Knowledge of anomalies related to styloid process may help in arriving at a correct diagnosis and will help in avoiding erroneous interpretation of radiographs. CT scans with coronal images of the upper cervical region provide excellent definition of the complex and adjacent soft tissues, thus it is used to evaluate the length of the stylohyoid complex. Currently, 3D spiral CT is the most advanced diagnostic imaging technique to evaluate the stylohyoid chain in spatial geometry with accurate length measurements. The detailed information about the course and relations of the stylohyoid chain and the relation of important adjacent anatomic structures also allows preoperative planning, thereby reducing the potential for iatrogenic intraoperative injury. [25]

Treatment of Eagle's syndrome is both non-surgical and surgical. Nonsurgical treatment includes reassurance, nonsteroidal anti-inflammatory drugs, physiotherapeutic neck exercises and steroid injections.[21] Injection of steroid into the lower tonsillar fossa is advised for patients who are unfit for surgery. Steinmann has reported good results with injection of a steroid solution or a long-acting anaesthetic at the lesser horn of the hyoid bone or the inferior aspect of tonsillar fossa.[26] The surgical treatment may be by intraoral or extraoral approach; however, extraoral approach for surgical trimming of elongated styloid process is preferred because of better visualization and decreased risk of deep space neck infection.[21] Eagle initially described tonsillo-styloidectomy by the intraoral route, where a transpharyngeal approach was used to extract the styloid process after tonsillectomy. There is no external scarring with this approach and low postoperative morbidity and complications.[26]

\section{CONCLUSION}

Eagle's syndrome associated with elongated styloid process is a rare clinical entity and is underdiagnosed for very common presentations of head and neck. Clinical palpation of tonsillar fossa complemented with radiography of skull base can make a diagnosis. It is important for the clinicians to be aware of nonsymptomatic anatomical variants also for elongated styloid process before reaching any conclusion in the head-neck pain. It is worth saying that with knowledge of non-symptomatic and symptomatic elongated styloid process along with meticulous examination and investigation a rare diagnosis of Eagle's syndrome can be made, for very common symptoms of throat. With recent trends of conservative approach our recent experience states that, although both modalities of treatment are available but nonsurgical approach should be reserved for patients unwilling or unfit for surgery. As authors we still advocate surgical approach of styloidectomy as the preferred modality to treat these cases, as this reduces overall morbidity and financial burden to the patients.

\section{REFERENCES}

1. Yavuz H, Caylakli F, Erkan AN, et al. Modified intraoral approach for removal of an elongated styloid process. J Otolaryngol Head Neck Surg 2011;40(1):86-90.

2. Johnson GM, Rosdy NM, Horton SJ. Manual therapy assessment findings in patients diagnosed with eagle's syndrome: a case series. Man Ther 2011;16(2):199-202.

3. Eagle WW. Elongated styloid process. Arch Otolaryngol 1948;47(5):630-640.

4. Eagle WW. Elongated styloid process, symptoms and treatment. Arch Otolaryngol 1958;67(2):172-176.
5. Eagle WW. Elongated styloid process: report of two cases. Arch Otolaryngol 1937;25(5):584-587.

6. Feldman VB. Eagle's syndrome: a case of symptomatic calcification of the stylohyoid ligaments. J Can Chiropr Assoc 2003;47(1):21-27.

7. Eagle WW. The symptoms, diagnosis and treatment of the elongated styloid process. Am Surg 1962;28:1-5.

8. Chandler JR. Anatomic variations of the stylohyoid complex and their clinical significance. Laryngoscope 1977;87:1692-1701.

9. Komala Nanjundaiah, Radhika PM, Veena Vidya Shankar, et al. Elongated styloid process: a report of two cadaveric cases. Int J Anat Res 2014;2(2):431-3.

10. Dunn-Ryznyk LR, Kelly CW. Eagle syndrome: a rare cause of dysphagia and head and neck pain. JAAPA 2010;23(12):28, 31-2, 48.

11. Colby CC, Del Gaudio JM. Stylohyoid complex syndrome: a new diagnostic classification. Arch Otolaryngol Head Neck Surg 2011;137(3):248-52.

12. Costantinides F, Vidoni G, Bodin C, et al. Eagle's syndrome: signs and symptoms. Cranio 2013;31(1):56-60.

13. Langlais RP, Miles DA, Van Dis ML. Elongated and mineralized stylohyoid ligament complex: a proposed classification and report of a case of eagle's syndrome. Oral Surg Oral Med Oral Pathol 1986;61(5):527-532.

14. Gossman JR Jr, Tarsitano JJ. The styloid-stylohyoid syndrome. J Oral Surg 1977;35(7):555-560.

15. Keur JJ, Campbell JP, McCarthy JF, et al. The clinical significance of the elongated styloid process. Oral Surg Oral Med Oral Pathol 1986;61(4):399-404.

16. Jakhar JK, Khanagwal VP, Aggarwal AD, et al. Unilaterally exceptionally elongated styloid process. J Punjab Acad Forensic Med Toxicol 2010;10(2):107-110.

17. Omnell KH, Gandhi C, Omnell ML. Ossification of the human stylohyoid ligament. Oral Surg Oral Med Oral Path 1998;85(2):226-232.

18. Ruprecht A, Sasrty KARH, Gerard P, et al. Variation in the ossification of the stylohyoid process and ligament. Dentomaxillofac Radiology 1988;17:61-66.

19. Balbuena L Jr, Hayes D, Ramirez SG, et al. Eagle's syndrome (elongated styloid process). South Med J 1997;90(3):331-334.

20. Jaju PP, Suvarna V, Parikh NJ. Eagle's syndrome-an enigma to dentists. J Indian Acad Oral Med Radiol 2007;19(3):424-429.

21. Murtagh RD, Caracciolo JT, Fernandez G. CT findings associated with eagle syndrome. AJNR Am J Neuroradiol 2001;22(7):1401-1402.

22. Balasubramanian $S$. The ossification of styloid ligament and its relation to facial pain. Br Dent J 1964;116:108111.

23. Baddour HM, McAnear JT, Tilson HB. Eagles syndrome case report. J Oral Surg 1978;46(4):486-494.

24. Nickel J, Sonnenburg M, Scheufler O, et al. Eagle syndrome: diagnostic imaging and therapy. Rontgenpraxis Zeitschrift fur Radiologische Technik 2003;55(3):108-113.

25. Alcade RE, Ueyama Y, Nishiyama A, et al. Diagnostic imaging of eagle's syndrome. Oral Radiol 1994;10(2):143-148.

26. Steinman EP. Styloid syndrome in absence of an elongated process. Acta Otolaryngol 1968;66:347-356. 